\title{
Are Family Table Foods Appropriate for Infants? Comparing the Nutritional Quality of Homemade Meals Adapted from the Family's Table Foods and Those Specially Prepared for Infants
}

\author{
Pérola Ribeiro1, Dirce Maria Sigulem², Tania Beninga Morais ${ }^{2,3^{*}}$ \\ ${ }^{1}$ Nutrition Course, Universidade Nove de Julho, São Paulo, Brazil \\ ${ }^{2}$ Postgraduate Program in Nutrition, Universidade Federal de São Paulo/UNIFESP, São Paulo, Brazil \\ ${ }^{3}$ Food Quality Control Laboratory, Universidade Federal de São Paulo/UNIFESP, São Paulo, Brazil \\ Email: "tania.pnut@epm.br
}

Received 23 April 2014; revised 25 May 2014; accepted 7 June 2014

Copyright (C) 2014 by authors and Scientific Research Publishing Inc.

This work is licensed under the Creative Commons Attribution International License (CC BY). http://creativecommons.org/licenses/by/4.0/

(c) (i) Open Access

\section{Abstract}

The Brazilian Ministry of Health recommends that by 8 months of age, children should eat the same types of foods consumed by the other members of the family. Thus, this study sought to evaluate whether the nutritional composition of meals specially prepared (SM) for children aged 7 to 18 months in low-income families was superior to that of meals adapted (AM) from the family's table foods. Protein, fat, carbohydrate, energy, dietary fiber, iron, sodium and sodium chloride values, were determined by chemical analyses and compared to dietetic guidelines. The infants' hemoglobin levels were also investigated. In total, sixty samples of the infants' lunch meal (51 AM and 9 SM) were taken for during a home visit. The values of protein, fat, carbohydrate, dietary fiber and energy of the AM were significantly lower, while the sodium and sodium chloride values were significantly higher, compared to those of the SM. The AM also contained significantly more water. No differences were seen with regard to iron values. Sodium chloride amounted for most of the sodium content. Neither the SM nor AM was adequate in terms of iron and sodium. All SM were adequate for protein and fat, whereas $A M$ showed significantly more samples with inadequate energy levels. SM fell within the Acceptable Macronutrient Distribution Range, while AM fell below the lower value for fat and slightly above the upper value for carbohydrate. The prevalence of anemia was $60 \%$ in the study population $(36 / 60)$. In conclusion, meals adapted from the family's table foods showed a lower nutrient density and a less balanced macronutrient range when com-

${ }^{*}$ Corresponding author.

How to cite this paper: Ribeiro, P., Sigulem, D.M. and Morais, T.B. (2014) Are Family Table Foods Appropriate for Infants? Comparing the Nutritional Quality of Homemade Meals Adapted from the Family's Table Foods and Those Specially Prepared for Infants. Food and Nutrition Sciences, 5, 1247-1254. http://dx.doi.org/10.4236/fns.2014.513135 
pared to meals specially prepared for infants. The main nutritional shortcomings, for both AM and SM, were the extremely low content of iron and the high content of sodium.

\title{
Keywords
}

\author{
Infant Food, Infant Nutrition, Food Composition, Food Analysis
}

\section{Introduction}

The weaning process represents a period of particular concern in developing countries because it is often accompanied by malnutrition, most commonly during the second semester of life, when foods other than breast milk are added to the diet [1]. It is well recognized that the period of $6-24$ months of age is one of the most critical time periods in the growth of the infant because at this time, children have high demands for nutrients and there are limitations in the quality and quantity of available foods. Infants older than 6 months require complementary foods of appropriate energy and nutrient densities in addition to breast milk to meet their physiologic needs. The relatively high energy requirements of young children, together with their limited gastric capacity, make it difficult for them to eat enough food, particularly if only a few meals per day are offered or if the foods have low energy density, or both [2]. Adequate complementary feeding is a matter of great concern for international health agencies, which have published technical guidelines on optimal complementary feeding practices [3] [4]. These guidelines address the following components: a) the introduction of foods other than breast milk at 6 mo of age; b) an adequate energy density and frequency of feeding of complementary foods; and, c) satisfactory nutrient density in these foods. Ensuring optimal complementary feeding practices for young children living in developing countries is a global public health priority because of their importance for the optimal growth, development, and well-being of infants and young children.

Studies on infant feeding have relied on dietary assessment methods, rather than chemical analysis, to estimate nutrient intake [5] [6]. However, dietary assessment methods have a number of potential errors, such as estimating the portion sizes in grams and the availability of a valid food composition table [7]. Moreover, few studies have addressed the nutritional quality of home-prepared baby foods based on chemical analyses [8]-[10]. These studies showed that home-prepared foods do not always have an adequate nutritional profile, even in developed countries, and show low contents of energy, protein, fat and iron and high levels of sodium.

Because the Brazilian Ministry of Health and the Pan American Health Organization recommend that children at 8 months of age should eat the same types of foods as those consumed by the rest of the family [3], this study was performed to evaluate whether the nutritional composition of meals specially prepared for children aged 7 to 18 months from low-income families is superior compared to that of meals adapted from the family's table foods. Macronutrients, energy, dietary fiber, iron, sodium and salt, expressed as the actual composition of foods as they were consumed by infants, were compared through chemical analyses to nutrient standards to identify potential nutritional shortcomings of both types of meals.

\section{Methods}

The Ethics Committee of the Universidade Federal de São Paulo approved this study, which was carried out in the city of Embu, located in the São Paulo metropolitan area of Brazil. This city has a human development index of 0.735 [11], and its infant mortality rate is $12.98 / 1000$ [12]. The subjects were selected from families registered in a field training program in Primary Health Care of the Department of Pediatrics of the Universidade Federal de Sao Paulo. From the daily scheduled medical appointments, the mothers of healthy and non-breastfed infants aged from 7 to 18 months were invited to participate, and a home visit was scheduled. Sixty infants were selected. The mothers/caregivers were visited by the first author (PR), a trained nutritionist, when the study objectives were explained to the mother and written permission was obtained. Mothers/caregivers were interviewed for socioeconomic and demographic information. The infants' families' socioeconomic status was assessed according to the criteria of the National Association of Business Research [13]. These criteria are income-independent and based on the head of household level of education. Additionally, points are awarded to the availability of items for comfort and domestic facilities. Samples of the infant's lunch meal were taken for 
chemical analysis. The hemoglobin concentration was measured with the cyanmethaemoglobin method, using a HemoCue- $\beta$-Hemoglobin-Photometer system (HemoCue AB, Ångelholm, Sweden). Anemia was diagnosed when the hemoglobin concentration fell below $11.0 \mathrm{~g} / \mathrm{dl}$ [14]. All children diagnosed as having anemia were referred to the Primary Health Care Center for treatment.

\subsection{Sampling Procedures}

A double portion of the home-made meal was prepared, from which one portion was given to the baby and the other was put into a plastic bag and taken to the laboratory. No prior instructions on meal preparation were given to the mother (or to the person who prepared the meal). Therefore, the mothers/caregivers prepared the meals in their usual fashion. Fifty-one meals were taken from the family's table food and then adapted by adding water to make a softer food suitable for infants (AM), while 9 meals were specially made for infants (SM). Staple foods consisted of rice, bean, meat, vegetables, pasta and sausage for both types of meals.

\subsection{Chemical Analyses}

The samples were analyzed in duplicate for moisture, protein, fat, dietary fiber, sodium, iron and ash [15]. The moisture content was obtained by heating the samples to $102^{\circ} \mathrm{C}$ until a constant weight was attained. The protein level was obtained by determination of total nitrogen by Kjeldahl method, whereas the fat was extracted by using the Soxhlet equipment. Dietary fiber was analyzed with an enzymatic-gravimetric method. Ash was obtained by incineration at $500^{\circ} \mathrm{C}-550^{\circ} \mathrm{C}$ until the ash was carbon-free. Sodium, sodium chloride and iron were determined in the ash solution by flame photometric, titrimetric and spectrophotometric methods, respectively. Carbohydrate content was determined by difference. The energy density was calculated using Atwater's factors, specifically by multiplying the protein and total carbohydrate content by $4 \mathrm{Kcal}$ and adding the result to the fat content multiplied by 9 Kcal.

\subsection{Comparison with Nutritional Guidelines}

As a framework to assess the nutritional quality of the homemade meals, the results were compared to the following guidelines of the Commission Directive 96/5/EC of the European Communities [16] (even though they are intended for processed cereal-based foods and baby foods for infants and young children): protein (minimum $4.0 \mathrm{~g} / 100 \mathrm{Kcal}$ ), fat (maximum $6.0 \mathrm{~g} / 100 \mathrm{Kcal}$ ), sodium (maximum $200 \mathrm{mg} / 100 \mathrm{~g}$ ) and iron (6.0 mg). Energy (minimum of $70 \mathrm{kcal}$ ) was assessed according to the Brazilian standard [17]. An acceptable macronutrient distribution range (AMDR) followed the intervals established for 1-to-3-year-old children (5\% to $20 \%$ of energy from protein; $30 \%$ to $40 \%$ from fat; and $45 \%$ to $65 \%$ from carbohydrate) because there are no recommended ranges for the first year of life [18].

\subsection{Statistical Analyses}

The statistical analyses were performed using the software Sigma Stat for Windows STAT32 ${ }^{\circledR}$ (SYSTAT Software Inc., 2005). The Mann-Whitney Test was used to compare the results of the chemical analyses according to the type of meal (SM and AM). Fisher's exact test was used to compare proportions of inadequate meals for energy density, protein, fat, iron, and sodium according to the type of meal, the mothers' socioeconomic class and primiparity, and the prevalence of anemia in the children of the SM and AM groups. The level of significance was $\mathrm{p}<0.05$.

\section{Results}

Socioeconomic and demographic characteristics of the SM and AM groups are shown in Table 1. The SM group included a significantly higher proportion of mothers who were younger, primiparous, and had significantly more years of education. No differences were seen with regard to the infants' age and the family's socioeconomic class; all families belonged to the two lowest strata of socioeconomic classes.

Table 2 shows the analytical results of the AM and SM groups. The values for protein, fat, carbohydrate, dietary fiber and energy in the AM group were lower $(\mathrm{p}<0.005)$, while those for sodium and sodium chloride were higher ( $<<0.005)$, compared to the SM group. The AM group showed higher $(\mathrm{p}<0.005)$ water levels. No 
Table 1. Socioeconomic and demographic characteristics.

\begin{tabular}{cccc}
\hline & SM $(\mathbf{n}=\mathbf{9})$ & AM $(\mathbf{n}=\mathbf{5 1})$ & Statistical analyses \\
\hline Infants' age (months) $^{\mathbf{a}}$ & $9.0(7.0-15.0)$ & $12.0(10.0-15.0)$ & $\mathrm{p}=0.198$ \\
Maternal age (years) $^{\mathbf{b}}$ & $22.0 \pm 5.0$ & $27.0 \pm 6.0$ & $\mathrm{p}=0.028$ \\
Maternal education (years) $^{\mathbf{b}}$ & $9.0 \pm 2.0$ & $7.0 \pm 3.0$ & $\mathrm{p}=0.013$ \\
Socioeconomic class $^{\mathbf{c}}$ & & 19 & $\mathrm{p}=0.462$ \\
C & 5 & 32 & $\mathrm{p}=0.032$ \\
D & 4 & 19 & 32 \\
Primiparous & & & \\
Yes & 7 & 2 & 32 \\
No & &
\end{tabular}

${ }^{\text {a }}$ median and $25^{\text {th }}$ and $75^{\text {th }}$ percentiles; ${ }^{\mathbf{b}}$ mean and standard deviation; ${ }^{\mathbf{c}}$ Fisher's exact test.

Table 2. Medians and $25^{\text {th }}$ and $75^{\text {th }}$ percentiles of macronutrients, dietary fiber, energy, iron, sodium and sodium chloride contents, according to the type of meal.

\begin{tabular}{cccc}
\hline Nutrient & SM $(\mathbf{n}=\mathbf{9})$ & AM $(\mathbf{n}=\mathbf{5 1})$ & Mann-Whitney Test \\
\hline Water $\mathbf{( g / 1 0 0 ~ g ) ~}$ & $74.2(70.1-86.6)$ & $89.2(74.8-90.4)$ & $\mathrm{p}<0.001$ \\
Protein $(\mathbf{g} / \mathbf{1 0 0} \mathbf{g})$ & $3.6(1.4-10.5)$ & $1.3(1.1-3.3)$ & $\mathrm{p}<0.001$ \\
Fat $(\mathbf{g} / \mathbf{1 0 0} \mathbf{g})$ & $3.1(0.6-3.7)$ & $0.9(0.5-1.5)$ & $\mathrm{p}<0.001$ \\
Carbohydrate (g/100 g) & $12.9(7.6-17.0)$ & $6.3(5.0-10.7)$ & $\mathrm{p}<0.001$ \\
Dietary fiber $(\mathbf{g} / \mathbf{1 0 0} \mathbf{g})$ & $2.6(1.9-2.9)$ & $1.6(1.2-2.3)$ & $\mathrm{p}<0.001$ \\
Energy (Kcal/100 g) & $93.8(45.2-111.9)$ & $38.4(32.4-87.2)$ & $\mathrm{p}<0.001$ \\
Iron (mg/100 g) & $0.2(0.1-0.9)$ & $0.2(0.1-0.3)$ & $\mathrm{p}=0.282$ \\
Sodium (mg/100 g) & $271.0(262.5-295.0)$ & $364.0(327.5-550.0)$ & $\mathrm{p}<0.001$ \\
Sodium chloride (mg/100 g) & $232.9(211.5-251.1)$ & $313.2(301.7-339.8)$ & $\mathrm{p}<0.001$ \\
\hline
\end{tabular}

differences were seen with regard to iron values, and sodium chloride amounted for most of the sodium content.

Table 3 presents the proportions of adequate meals. Neither SM nor AM was adequate in terms of providing sufficient iron and sodium. All SM were adequate for protein and fat, whereas significantly more of the AM samples were inadequate for energy.

The SM samples presented a more balanced macronutrient distribution range (Table 4). Overall, the SM samples fell into the AMDR intervals, while the AM samples fell below the lower value for fat and slightly above the upper value for carbohydrate.

The prevalence of anemia among the infants was 60\% (36/60). This prevalence was lower in the SM group (44.4\%, 4/9) when compared to the AM group (62.7\%, 32/51), although no statistically significant difference was observed (Fisher's exact test; $\mathrm{p}=0.47$ ).

\section{Discussion}

Complementary feeding should be timely, meaning that all infants should start receiving foods in addition to breast milk at 6 months of age an onwards; adequate, meaning that the nutritional value of the complementary foods should fulfill the needs of the rapidly growing child; and appropriate, meaning that the foods should be diverse, of an appropriate texture and given in sufficient quantity [19].

Current guidelines recommend that by 8 months [3] or 12 months of age [4], infants should eat the same types 
Table 3. Number and percentages of homemade meals adequate for energy density, protein, fat, iron, and sodium according to the type of meal.

\begin{tabular}{|c|c|c|c|}
\hline & $\operatorname{SM}(n=9)$ & $A M(n=51)$ & Fisher's exact test \\
\hline Energy density (Kcal/100 g) & 6 & 14 & \\
\hline (minimum: 70 Kcal/100 g) & $(67.0 \%)$ & $(27.5 \%)$ & $\mathrm{p}=0.049$ \\
\hline Protein (g/100 Kcal) & 9 & 48 & \\
\hline (minimum: $3.0 \mathrm{~g} / 100 \mathrm{Kcal}$ ) & $(100 \%)$ & $(94.0 \%)$ & $\mathrm{p}=1.000$ \\
\hline Fat (g/100 Kcal) & 9 & 46 & \\
\hline (maximum: $4.5 \mathrm{~g} / 100 \mathrm{Kcal}$ ) & $(100 \%)$ & $(90.2 \%)$ & $\mathrm{p}=1.000$ \\
\hline Iron (mg/100 g) & 0 & 0 & \\
\hline (minimum: 6 mg/100 g) & $(0 \%)$ & $(0 \%)$ & $\mathrm{p}=1.000$ \\
\hline Sodium (mg/100 g) & 0 & 0 & \\
\hline (maximum: 200 mg/100 g) & $(0 \%)$ & $(0 \%)$ & $\mathrm{p}=1.000$ \\
\hline
\end{tabular}

Table 4. Mean percentages of energy from macronutrients of homemade meals according to the type of meal.

\begin{tabular}{ccc}
\hline From protein (expected range: $\mathbf{5 \%}-\mathbf{2 0} \%)$ & SM (n= 9) & AM (n= 51) \\
From fat (expected range: $\mathbf{3 0} \% \mathbf{- 4 0 \% )}$ & $15 \%$ & $14 \%$ \\
From carbohydrate (expected range: $\mathbf{4 5 \%}-\mathbf{6 5 \% )}$ & $30 \%$ & $21 \%$ \\
\hline
\end{tabular}

of foods as consumed by the rest of the family. Food consistency and variety should gradually increase with age and adapt to the child's specific requirements and abilities [4]. However, the results of this study showed that, overall, meals adapted from the family's table food had a lower nutrient density when compared to meals specially prepared for infants. The family's food provided less energy, protein, fat, and fiber and more sodium and showed less balanced macronutrient ranges. Additionally, these meals had significantly more water, likely because of the need for pureed, mashed or semi-solid foods suitable for infants, which caused a dilution of nutrients and energy. When compared to the current nutritional guidelines, most of AM samples met the standards for macronutrients, although approximately $70 \%$ of them failed to meet the standard for energy. Additionally, fat contributed to only approximately $20 \%$ of the energy in these meals (at least $30 \%$ should have been expected). These are worrying findings because the first year of life is a period of very rapid growth, with the weight of a normal infant tripling by 12 months of age [20]. Both the quantitative and qualitative nutritional requirements of infants and toddlers are different from those of older children and adults [21]. Thus, the inadequacies in macronutrients and energy found in the AM might jeopardize the infant's growth, development and health. A high content of sodium and low content of iron were the main nutritional inadequacies found in this study, both in SM and AM, and similar findings have been reported in another region of the country [10].

Meals adapted from the family's foods showed a significantly higher content of sodium. Most of this sodium came from added table salt (sodium chloride), reflecting the Brazilian adult population's habit of consuming salt in quantities well above the recommended level [22]. In infants, previous studies using aqueous solutions showed that a preference for salty taste emerges at about the age of 4 months and persists until the age of 2 years [23]. Once salting preferences are established, habit may perpetuate these habits and hamper recommendations to reduce the sodium intake [24], as recommended by international health authorities. As detrimental effects of excessive sodium consumption in early life and high blood pressure in the first year of life and during adolescence have been found [25] [26], the Brazilian Society of Pediatrics (manual, 2012) has advocated that baby foods should be prepared with no sodium chloride [27].

Both the SM and AM presented extremely low iron concentrations; in particular, the iron contents in the meals accounted for only to $2.0 \%$ to $3.0 \%$ of the recommended dietary intake for iron [28]. Thus, it is not sur- 
prising that anemia was present in $60 \%$ of the infants. These are alarming findings because there is a critical period when iron deficiency may result in long-lasting damage that can alter functioning in adulthood [29].

The reasons why the meals were so low in iron are unclear, as some staple foods such as beans, meat and sausage have some amount of iron. Further studies are needed to clarify this point; however, we suggest that, most likely, the amount of such foods in the meals were not sufficient to meet the children's needs. Additionally, caregivers might feel that they were not suitable for young children because they may some have difficulties chewing thicker foods, although scientific findings recommend that food consistency and variety should gradually increase as the infant gets older, adapting to their changing requirements and abilities [1].

Some limitations of the present study must be acknowledged. For instance, this study was conducted in only one city. Therefore, the results may not be generalizable to the entire country, although our findings were corroborated by a study conducted in another region of the country [10]. Replication of these findings in other jurisdictions and with a larger sampling frame would strengthen the generalizability of the study findings to other regions and countries. The strengths of this study include the use of duplicate food collection methods, which is considered a method of greater accuracy [7], and the chemical analyses of the samples. Therefore, the results expressed the actual composition of the foods consumed by the infants.

\section{Conclusion}

The results of this study showed that, overall, meals adapted from the family's table food (AM) had a lower nutrient density when compared to meals specially prepared for infants (SM). In particular, the family's food provided less energy, protein, fat, and fiber and more sodium and showed less balanced macronutrient ranges. The main nutritional shortcomings, for both AM and SM, were the extremely low content of iron and the high content of sodium. Further studies should address whether caregivers should prepare meals that are nutritionally adequate, especially for infants during the second semester of life. Moreover, the family's diet should be modified toward a healthier pattern to meet the infant's needs, which will also benefit all family members.

\section{Acknowledgements}

The authors would like to thank the Division of General Pediatrics and Primary Health Care of the Department of Pediatrics at the Universidade Federal de São Paulo, the staff of the basic health unit where the study was carried out and the mothers who kindly opened their homes and provided the samples.

\section{Financial Support}

This research was partially funded by FAPESP—Fundação de Amparo à Pesquisa [São Paulo Research Foundation] of the State of São Paulo government.

\section{Conflict of Interest}

None.

\section{Authorship}

PR designed and conducted the research, analyzed the data and wrote the paper. DMS designed the research and analyzed the data. TBM designed the research, analyzed the data, wrote the paper and had primary responsibility for the final content.

\section{Ethics Committees}

The Ethics Committee of the Universidade Federal de São Paulo gave approval for this study.

\section{References}

[1] Dewey, K.G., Peerson, J.M., Heining, M.J., Nommsen, L.A., Lönnerdal, N.B., Romaña, G.L., et al. (1992) Growth Patterns of Breast-Def Infants in Affluent (United States) and Poor (Peru) Communities: Implications for Timing of Complementary Feeding. The American Journal of Clinical Nutrition, 56, 1012-1018. 
[2] Islam, M.M., Peerson, J.M., Ahmed, T., et al. (2006) Effects of Varied Energy Density of Complementary Foods on Breast-Milk Intakes and Total Energy Consumption by Healthy, Breastfed Bangladeshi Children. American Journal of Clinical Nutrition, 83, 851-858.

[3] Ministry of Health [Ministério da Saúde] (2002) Food Guide for Children under Two Years [Guia alimentar Para Crianças Menores de 2 Anos]. Ministério da Saúde [Ministry of Health], Brasília. Organização Pan Americana da Saúde [Pan American Health Organization].

[4] World Health Organization. (2005) Guiding Principles for Feeding Non-Breastfed Children 6-24 Months of Age. World Health Organization, Geneva.

[5] Faber M. (2005) Complementary Foods Consumed by 6-12-Month-Old Rural Infants in South Africa Are Inadequate in Micronutrients. Public Health Nutrition, 8, 373-391. http://dx.doi.org/10.1079/PHN2004685

[6] Kimmons, J.E., Dewey, K.G., Haque, E., et al. (2005) Low Nutrient Intakes among Infants in Rural Bangladesh Are Attributable to Low Intake and Micronutrient Density of Complementary Foods. Journal of Nutrition, 135, 444-451.

[7] Welch, A.A. (2005) Dietary Intake Measurement: Methodology. In: Caballero, B., Allen, L. and Prentice, A., Eds., Encyclopedia of Human Nutrition, 2nd Edition, Elsevier, Amsterdam, 7-16. http://dx.doi.org/10.1016/B0-12-226694-3/00089-2

[8] Stordy, B.J., Redfern, A.M. and Morgan, J.B. (1995) Healthy Eating For Infants—Mothers' Action. Acta Paediatrica, 84, 733-741. http://dx.doi.org/10.1111/j.1651-2227.1995.tb13746.x

[9] van den Boom, S.A.M., Kimber, A.C. and Morgan, J.B. (1997) Nutritional Composition of Home-Prepared Baby Meals in Madrid. Comparison with Commercial Products in Spain and Home-Made Meals in England. Acta Paediatrica, 86, 57-62. http://dx.doi.org/10.1111/j.1651-2227.1997.tb08833.x

[10] Portella, M.B., Morais T.B. and Morais M.B. (2010) Excess Sodium and Insufficient Iron Content in Complementary Foods. Jornal de Pediatria, 86, 303-310.

[11] Brazilian Institute of Geography and Statistics [Instituto Brasileiro de Geografia e Estatística]. http://www.cidades.ibge.gov.br

[12] State System of Data Analysis Foundation [Fundação Sistema Estadual de Análise de Dados]. http://www.seade.gov.br

[13] National Association of Business Research [Associação Brasileira de Empresas de Pesquisa]. Criteria of Economic Classification [Critério de classificação econômica]. http://www.abep.org

[14] World Health Organization (2001) Iron Deficiency Anaemia: Assessment, Prevention and Control. Genebra.

[15] Association of Official Analytical Chemists (2007) Official Methods of Analysis of AOAC International: Current through Revision 2. AOAC International.

[16] European Communities (2006) Commission Directive 2006/125/EC on Processed Cereal-Based Foods and Baby Foods for Infants and Young Children. Official Journal of the European Union.

[17] Ministry of Health [Ministério da Saúde] (2009) Complementary Foods for Infants and Young Children [Alimentos de Transição Para Lactentes e Crianças de Primeira Infância].

[18] Institute of Medicine. Dietary Reference Intakes (DRI) (2002) Dietary Reference Intakes for Energy, Carbohydrate, Fiber, Fat, Fatty Acids, Cholesterol, Protein and Amino Acids. National Academy Press, Washington DC.

[19] World Health Organization (2002) Report of Informal Meeting to Review and Develop Indicators for Complementary Feeding. Washington DC.

[20] Fomon, S.J. (1967) Body Composition of the Male Reference Infant during the First Year of Life. Pediatrics, 40, 863870.

[21] Akre, J. (1989) Infant Feeding. The Physiological Basis. Bulletin of the World Health Organization, 67, 1-108.

[22] Sarno, F., Claro, R.M., Levy, R.B., et al. (2009) Estimated Sodium Intake by the Brazilian Population, 2002-2003. Revista de Saúde Pública, 43, 219-225. http://dx.doi.org/10.1590/S0034-89102009005000002

[23] Bouhlal, S., Issanchou, S. and Nicklaus, S. (2011) The Impact of Salt, Fat and Sugar Levels on Toddler Food Intake. British Journal of Nutrition, 105, 645-653. http://dx.doi.org/10.1017/S0007114510003752

[24] Leshem, M. (2009) Biobehavior of the Human Love for Salt. Neuroscience and Biobehavioral Reviews, 33, 1-17. http://dx.doi.org/10.1016/j.neubiorev.2008.07.007

[25] Hofman, A., Hazebroek, A. and Valkenburg, H.A. (1983) A Randomized Trial of Sodium Intake and Blood Pressure in Newborn Infants. JAMA, 250, 370-373. http://dx.doi.org/10.1001/jama.1983.03340030030023

[26] Geleijnse, J.M., Hofman, A., Witteman, J.C., et al. (1997) Long-Term Effects of Neonatal Sodium Restriction on Blood Pressure. Hypertension, 29, 913-917. http://dx.doi.org/10.1161/01.HYP.29.4.913

[27] Brazilian Society of Pediatrics (2012) Dietary Guidelines for Infants, Preschoolers, Adolescents and School Feeding. 
3rd Edition, Brazilian Society of Pediatrics, Rio de Janeiro.

[28] Institute of Medicine (2002) Dietary Reference Intakes (DRI). Dietary References Intakes for Energy, Carbohydrate, Fiber, Fat, Protein and Aminoacids National Academy Press, Washington DC.

[29] Beard, J.L. (2008) Why Iron Deficiency Is Important in Infant Development. Journal of Nutrition, 138, $2534-2536$. 
Scientific Research Publishing (SCIRP) is one of the largest Open Access journal publishers. It is currently publishing more than 200 open access, online, peer-reviewed journals covering a wide range of academic disciplines. SCIRP serves the worldwide academic communities and contributes to the progress and application of science with its publication.

Other selected journals from SCIRP are listed as below. Submit your manuscript to us via either submit@scirp.org or Online Submission Portal.
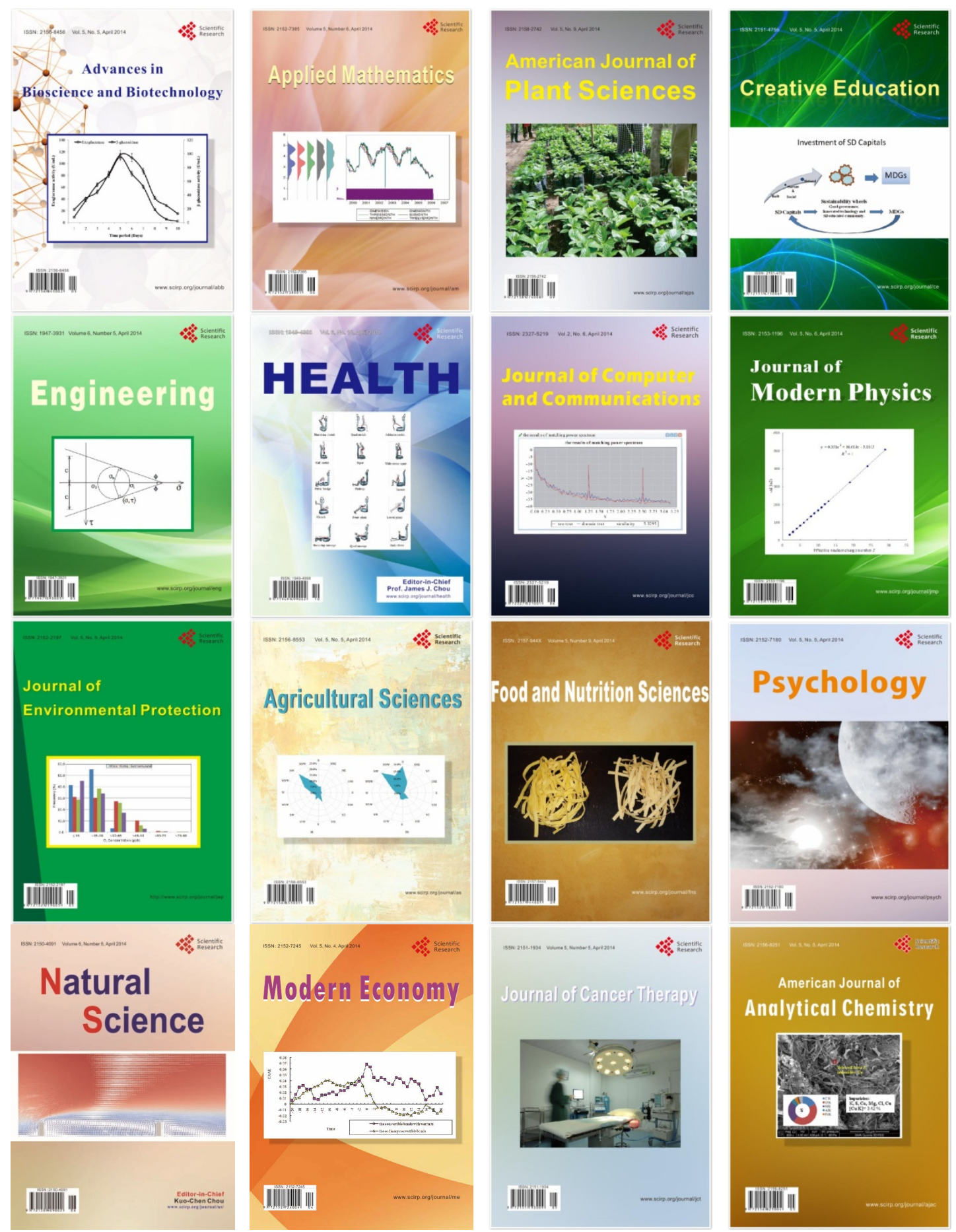